\title{
Artificial and Natural Sensors in FES-assisted Human Movement Control
}

\author{
Peter H. Veltink ${ }^{*}$, Thomas Sinkjær ${ }^{* *}$, Chris T.M. Baten ${ }^{* * *}$, Piet Bergveld ${ }^{*}$, Jaap van der Spek ${ }^{*}$ \\ and Morten Haugland ${ }^{* *}$ \\ *Institute for Biomedical Engineering (BMTI), University of Twente, Enschede, the Netherlands \\ ${ }^{* *}$ Center for Sensory-Motor Interaction (SMI), Aalborg University, Aalborg, Denmark \\ ${ }^{* * *}$ Roessingh Research and Development bv, Enschede, the Netherlands \\ *E-mail: P.H.Veltink@el.utwente.nl
}

\begin{abstract}
The availability of small and light micromachined sensors for human use and the demonstration that useful signals can be derived from the natural sensors of the human body have enabled new developments in the area of feedback controlled FES assistance of human movements. This paper presents the need for sensory feedback in FES control systems and gives an overview of available artificial sensors for human use and progress in the derivation and application of signals from natural sensors.
\end{abstract}

\section{INTRODUCTION}

Feedback control of FES assisted movement control requires relevant sensory signals for feedback. Physical quantities relevant for feedback in FES assisted movement control can be of kinematic or kinetic nature. Relevant kinematic quantities are angles and angular velocities of body segments or joints as well as position, velocity and acceleration of specific points of the body. Relevant kinetic quantities are the pressure distribution under the feet or on the skin surface of the hand, joint moments and forces or moments exerted on support devices.

These physical quantities can be used in the control of FESassisted human movements at several hierarchical control levels (fig. 1). At the highest level, the sensory signals can give information about the movement intention of the user, i.e.

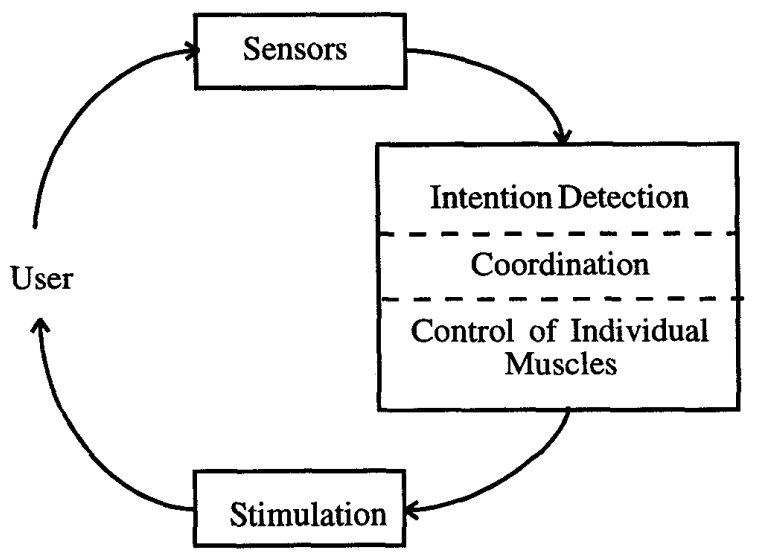

Figure 1. Hierarchical FES control system. identify the movement task the user wants to perform. At the intermediate control level, sensory signals give information about state transitions in a state model of a specific movement task. At the lowest level, sensory signals are used for continuous feedback control of the effector system, which are the electrically stimulated muscles.

The objective of this paper is to give an overview of recent developments in application of artificial and natural sensors for measuring relevant quantities for control of FES and to review some examples of proposed use of these sensors in feedback control of FES.

\section{Artificial Sensors \\ ARTIFICIAL AND NATURAL SENSORS \\ Relevant artificial sensors for feedback in FES movement} control systems are:

1. force sensors for measuring forces and pressure distributions under feet and at walking aids. Force Sensitive Resistive (FSR) sensors as well as Force Sensitive Capacitive devices measure perpendicular forces. Unfortunately, sensors for measuring shear forces are not available.

2. Goniometers can be used for measuring joint angles. Flexible goniometers and potentiometric goniometers for external fixation are available. However, they are vulnerable because they cross joints and need two points of attachments.

3. Inertial sensors (accelerometers/gyroscopes) have great

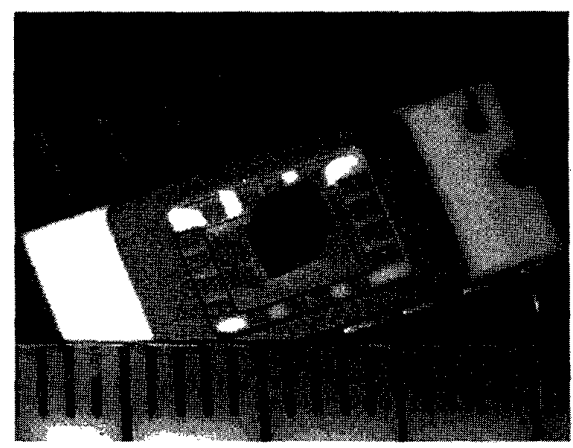

Figure 2. Micromachined triaxial accelerometer developed at University of Twente [1]. 
potential in measuring human body movements in ambulatory systems like FES. Their human application has been investigated in recent years since small and light micromachined sensors became available. A triaxial accelerometer/gyroscope sensor system can provide 3D information about acceleration, angular velocity and angle of a body segment, needing only one point of attachment. A new triaxial accelerometer for feedback in FES systems is presented in figure 2 [1].

\section{Natural Sensors}

Recently, it has been demonstrated that signals can be derived chronically from natural sensors of the human body $[2,3]$. It specifically concerns signals from the skin sensors, providing information about the pressure distribution at the skin. This sensory information is especially sensitive for phasic components of skin pressure. In contrast to available artificial pressure and force sensors, both perpendicular and shear components of skin pressure are being sensed.

Recent animal experiments have shown that signals from the joint and muscle afferents can be derived with nerve cuff electrodes, giving information about joint angles [4]. However, this has not been demonstrated in humans yet.

\section{TRANSFERING SENSOR SIGNALS TO PHYSICAL QUANTITIES}

In many of the feedback applications in FES control physical quantities need to be derived from the sensory signals. This derivation requires processing of the sensory signals on the basis of a physical model of the sensors. Such a physical sensor model needs to be identified, requiring the choice of the model structure and the value of the model parameters. The model structure can often be identified using physical knowledge. Identification of the model parameters often requires calibration experiments. If the sensor characteristics change with time, recalibration may be required.

Several examples can be given of sensor model identification:

1. Lötters et al. reported on a method for automatic in-use calibration of the offsets and gains of a triaxial accelerometer [5]. This procedure requires no explicit calibration experiments and model parameters are constantly adapted during use. This recalibration procedure uses the gravitational acceleration as a reference for all quasi-static periods which happen to occur during use. Adequate and constant estimation of sensor model parameters requires a certain frequency of quasi-static periods during use under varying orientations.

2. In a complete triaxial inertial sensor system the accelerometer and gyroscope outputs can be used for mutual calibration, because they are physically dependent: the orientation of the sensor system can be derived at any moment by processing the angular velocity measured by the gyroscope, solving a suitable differential equation [6]. During static phases, the accelerometer gives information about the direction of gravity, which can be used to recalibrate offset angles used for deriving angles from the gyroscope signals $[7,8,9]$. Figure 3 shows a reconstruction of knee angle from a 3D inertial sensor on thigh and shank, compared to knee angle measurement with a VICON optokinetic measurement system. The orientation of the sensor with respect to the leg segments was identified from a reference measurement of knee flexion and extension.

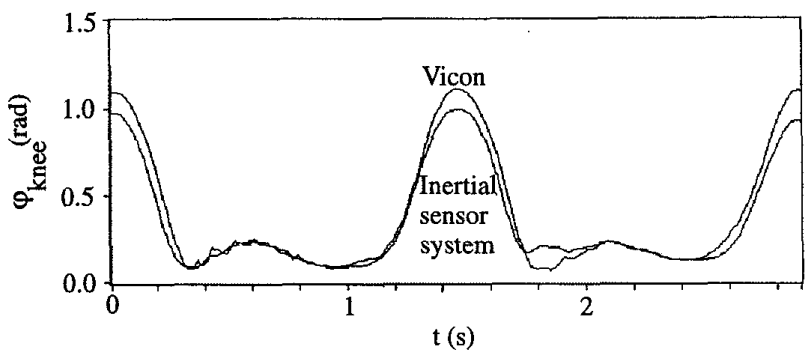

Figure 3. Reconstruction of knee angle from two $3 D$ inertial sensor system, one on the thigh and one on the shank. The sensor axes were directed arbitrarily. The orientation of the sensors with respect to the knee axes was obtained from a reference measurement in which the knee was flexed and extended several times. For comparison, the knee angle reconstructed with the VICON optokinetic measurement system is given.

3. A nonlinear model of the natural skin sensor dynamics was obtained experimentally at Aalborg University [2, 10]. This model relates physical quantities (applied skin pressure) with sensor output (signals measured with a cuff around the sensory nerve). A problem in the application of this model is that it can not be inverted, which is required when estimating physical quantities from measured signals.

It should be noted that the conversion of sensory signals to physical quantities is not required for all approaches in FES feedback control. The sensory signals can be used by artificial intelligent or learning neurofuzzy controllers which will learn the meaning of the sensory signals implicitly $[11,12]$. However, in order to use explicit knowledge and objectives in control of FES, feedback signals need to be expressed in welldefined physical quantities.

\section{APPLICATIONS OF ARTIFICIAL AND NATURAL SENSORS IN FES CONTROL SYSTEMS}

Signals of artificial and natural sensors can be used for feedback at several hierarchical levels of FES control systems (fig. 1). Some examples will be given at each level:

The highest control level: intention detection:

1. The intention of the user to perform a certain movement task can be identified from actions of the healthy part of the body. These actions can be assessed by measuring body movements, posture and interface forces with the environment $[13,14,15]$ 
The intermediate control level: coordination of movement:

2. Stance and swing phase detection are required for footdrop stimulation in hemiplegic subjects. This detection is normally done by a heel switch [16]. However, such a heel switch appears to be vulnerable in use. Alternative sensor systems have been reported: using the natural sensors of the sole of the foot $[12,17]$ or accelerometers $[18,19]$

3. Several finite state control approaches and sensor systems for FES supported execution of mobility tasks like gait and standing in paraplegics have been reported $[13,14]$.

Low level control:

4. Haugland et al. demonstrated the control of hand neuroprostheses by feedback from the natural sensors of the skin $[10,20]$.

5. Franken et al, described a cycle-to-cycle control system for control of step size during gait, using goniometers for measuring hip angle [21]. Information about step size can however also be obtained by inertial sensors [22].

6. Signals from natural sensors of the skin of the foot, inertial sensors on the body and interface forces with support devices (e.g. crutches) may deliver useful sensory information for FES-assisted control of body balance [23, 24]. Figure 4 displays the response of the position of center of pressure and crutch force on a stimulation burst applied to the hamstrings during stance.

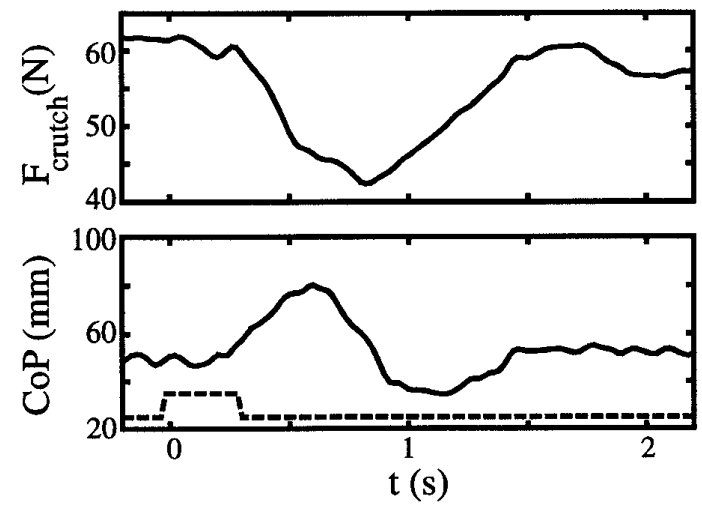

Figure 4. Center of Pressure (CoP) and crutch force response to a stimulation burst on hamstrings of $0.3 \mathrm{~s}$ duration (indicated by dashed line), starting on $t=0 \mathrm{~s}$. The stimulation burst was superimposed on a continuous co-contraction stimulation applied to hamstrings and quadriceps to control hip stiffness. Not shown are kinematic responses to the disturbance, which were measured with inertial sensors on the body. CoP may be monitored by natural sensors of the skin of the foot or by artificial pressure sensors under the feet. The signals from these sensors may be valuable in the feedback control of FES-assisted posture control. This preliminary experiment was performed on a healthy subject, standing with locked knees.

\section{DISCUSSION}

New developments in the area of human movement measurement and control have been made possible by the fairly recent development of light and small micro-machined sensors $[1,25]$ and the recent demonstration that useful signals from natural sensors of the human body can be derived $[2,10]$.

It is to be expected that human applications of these sensors will be further developed in the coming years. Apart from feedback in control of FES several other application fields are under development: ambulatory monitoring [26], back load assessment [7], intelligent prostheses, etc. Particularly interesting for FES applications are sensors that are potentially implantable, like inertial sensors, and implanted electrodes that derive natural sensor signals from nerves. They can enable the development of total implant feedback controlled FES systems.

\section{ACKNOWLEDGEMENTS}

We acknowledge the support by the Dutch Technology Foundation STW, the Dutch Ministry of Economic Affairs (project AMBER), the EU Training and Mobility of Researchers Program (project NEUROS) and the BIOMED2 program (project SENSATIONS), the Danish National Research Foundation and the Danish National Research Council.

\section{REFERENCES}

[1] J.C. Lötters, J.G. Bomer, A.J. Verloop, W. Olthuis, P.H. Veltink, P. Bergveld, Design, fabrication and characterization of a highly symmetrical capacitive triaxial accelerometer, Sensors and Actuators A, Vol. 66, 1998, pp. 205-212.

[2] R.R. Riso, P.J. Slot, M.K. Haugland, T. Sinkjær, Characterization of cutaneous nerve responses for control of neuromotor prostheses, $5^{\text {th }}$ Vienna International Workshop on Functional Electrical Stimulation, Aug. 1995, Vienna, pp. 335-338.

[3] B. Upshaw, T. Sinkjær, Digital signal processing algorithms for the detection of afferent nerve activity recorded from cuff electrodes in man, IEEE Trans. Rehab. Eng., in press.

[4] R.R. Riso, F.K. Mosallaie, T. Sinkjær, Nerve cuff recordings of muscle afferent activity from tibial and peroneal nerves in rabbit during passive ankle motion, IEEE Trans. Rehab. Eng., provisionally accepted.

[5] J.C. Lötters, J. Schipper, P.H. Veltink, W. Olthuis and P. Bergveld, Procedure for in-use calibaration of triaxial accelerometers in medical applications, Sensors and Actuators A, vol. 68, 1998, pp. 221-228.

[6] B.T.M. van Deurzen, P.H. Veltink, C.T.M. Baten, P. Bergveld, J.C. Lötters, Movement Analysis using Accelerometers and Gyroscopes, Proceedings of the $11^{\mathrm{th}}$ Congress of the International Society of Electrophysiological Kinesiology, Enschede, October 27-30, 1996, pp. 91-92.

[7] C.T.M. Baten, P. Oosterhoff, I. Kingma, P.H. Veltink, H.J. Hermens, Inertial Sensing in ambulatory load estimation, Proceedings of the IEEE Eng. in Med. \& 
Biol. Soc., 18th Annual Int. Conf., Amsterdam, October 31 - November 3 1996, 2pp.

[8] P.H. Veltink, D.M. Nieuwland, J. Harlaar, C.T.M. Baten, Inertial Sensing in a Hand Held Dynamometer, Proceedings of the IEEE Eng. in Med. \& Biol. Soc., 18th Annual Int. Conf., Amsterdam, October 31 November 3 1996, 2pp.

[9] P.H. Veltink, C.T.M. Baten, J.C. Lötters, R.E. Mayagoitia, Kinematic Sensing for Control of FES Combining a 3D Accelerometer and Gyroscope System, Proc. $1^{\text {st }}$ Annual Conf. Of the International Functional Electrical Stimulation Society, Cleveland, May 14-16 1996, p. 22.

[10] M. Haugland, T. Sinkjær, Control with natural sensors, in: J. Winters and P. Crago (eds.), Synthesis of Posture and Movement in Neural Prostheses, 1998, in press

[11] R. Williamson and B.J. Andrews, Sensors for FES Control, Proc. $2^{\text {nd }}$ Annual Conf. of IFESS, Vancouver, 16-21 August 1997, pp. 213-215.

[12] A. Kostov, T. Sinkjær, B. Upshaw, Gait event discrimination using ALNs for control of FES in footdrop problem, $18^{\text {th }}$ Annual International Conference of the IEEE EMBS, Amsterdam, the Netherlands, 1996, 2 pp.

[13] B.J. Andrews, R.W. Barnett, G.F. Phillips, C.A. Kirkwood, Rule-based Control of a Hybrid FES Orthosis for Assisting Paraplegic Locomotion, Automedica, vol. 11, 1989, pp. 175-199.

[14] P.H. Veltink, W. de Vries, H.J. Hermens, G. Baardman, M. IJzerman, S. Heinze, A.V. Nene, G. Zilvold, H.B.K. Boom, A Comprehensive FES Control System for Mobility Restoration in Paraplegics, in: A. Pedotti, M. Ferrarin, J. Quintern and R. Riener (eds.), Neuroprosthetics - from Basic Research to Clinical Applications, Springer Verlag, 1996, pp. 163-169.

[15] P.H. Veltink, H.B.J. Bussmann, W. de Vries, W.L.J. Martens, R.C. van Lummel, Detection of Static and Dynamic Activities using Uni-axial Accelerometers, IEEE Trans. Rehab. Eng., 1996, Vol. 4, pp. 375-385.

[16] W.T. Liberson, h.I. Holmquest, D. Scott and M. Dow, Functional electrotherapy in stimulation of the peroneal nerve synchronized with the swing phase of the gait of hemiplegic patients, Arch. Phys. Med. Rehab., vol. 42, 1961, pp. 202-205.
[17] M. Haugland, T. Sinkjær, Cutaneous whole nerve recordings used for correction of footdrop in hemiplegic man, IEEE Trans. Rehab. Eng., 1995, Vol. 3, pp. 307317.

[18] A.Th.M. Willemsen, F. Bloemhof, H.B.K. Boom, Automatic Stance-Swing Phase Detection from Accelerometer Data for Peroneal Nerve Stimulation, IEEE Trans. Biomedical Engineering, vol. 37, 1990, pp. 1201-1208.

[19] R. Dai, R.B. Stein, B.J. Andrews, K.B. James, M. Wieler, Application of Tilt Sensors in Functional Electrical Stimulation, IEEE Trans. Rehabil. Eng., vol. 4, 1996, pp. 63-72.

[20] M. Haugland, A. Lickel, J. Haase, T. Sinkjær, Hand neuroprosthesis controlled by natural sensors, IEEE Trans. Rehab. Eng., accepted.

[21] H.M. Franken, P.H. Veltink, G. Baardman, R.A. Redmeijer, H.B.K. Boom, Cycle-to-Cycle Control of the Swing Phase of Paraplegic Gait Induced by Surface Electrical Stimulation, Med. \& Biol. Eng. \& Comput., 1995, vol. 33, pp. 440-451.

[22] M.P. Koper, W. de Vries, P.H: Veltink, Step Length Estimation by means of Accelerometry - a Preliminary Investigation, in: P.H. Veltink and R.C. van Lummel, Dynamic Analysis using Body Fixed Sensors, ISBN 909007328-0, July 1994, pp. 51-55.

[23] W. Jensen, L.N.S. Andreasen, P.H. Veltink, R.E. Mayagoitia, Identification of the Relationship between Center of Pressure and Ankle Angle during Standing of Normal Subjects, Proceedings of the IEEE Eng. in Med. \& Biol. Soc., 18th Annual Int. Conf., Amsterdam, October 31 - November 3 1996, 2pp.

[24] L.N.S. Andreasen, W. Jensen, P.H. Veltink, J.J. Struijk, Natural Sensory Feedback for Control of Standing, Proceedings of the IEEE Eng. in Med. \& Biol. Soc., 18th Annual Int. Conf., Amsterdam, October 31 . November 3 1996, 2pp.

[25] J. Söderkvist, Micromachined gyroscopes, Sensors and Actuators A, vol. 43, 1994, pp. 65-71.

[26] J.B.J. Bussmann, P.H. Veltink, F. Koelma, R.C. van Lummel, H.J. Stam, Ambulatory Monitoring of Mobility-Related Activities: the Initial Phase of the Development of an Activity Monitor, Eur. J. Phys. Med. Rehabil, vol. 5, 1995, pp. 2-7. 